\title{
Sour Apple Concentrate: processing essentials and organoleptic properties
}

\author{
Ossama Dimassi ${ }^{*}$, Ghenwa Aboul Hosn ${ }^{1}$, Raymond Akiki², Mohamed \\ Rached $^{3}$
}

\author{
${ }^{1}$ Department of Nutrition and Food Science, Lebanese International University, Beirut, Lebanon \\ ${ }^{2}$ Department of Business Administration, Lebanese International University, Beirut, Lebanon \\ ${ }^{3}$ Department of Biomedical Sciences, Lebanese International University, Beirut, Lebanon \\ *Corresponding author: odimassi@gmail.com
}

\begin{abstract}
The aim of this study is to have a new apple-based product with relatively long shelf life. Sans Pareille, Malus domestica, 'mouwachah' was harvested prematurely and sour-apple-concentrate was produced following a traditional Lebanese recipe used to produce pome-granate sauce (PS). Part of the prepared SAC had Salt added (SACSa), another citric acid (SACCA) and both Salt and Citric Acid (SACSACA). The higher the Brix the significantly higher the density and total caloric content and significantly lower water-acitivity. There was no significant difference in caloric value on Dry-Matter basis. Furthermore, SAC and SACSa had significantly lower $p H$ only at $75^{\circ}$ Brix. Within SACCA and SACSaCA pH at the $75^{\circ}$ Brix is significantly the lowest compared to $\mathrm{pH}$ values at 55 and $65^{\circ}$ Brix. The higher the Brix-level the significantly higher the Titratable Acidity (TA) in all products except in SACSaCA where it was significantly higher only at $75^{\circ} B r i x$. Within the same Brix level, TA of SAC and SACSa did not differ significantly, while TA was significantly lower than TA of SACCA and $S A C S a C A$. These products were compared to traditional products PS and grape-verjuice. In terms of aroma, appearance, texture, taste, sourness, sweetness, overall-acceptability and average score of the Sour Apple concentrate products, except for SACSaCA, scored significantly higher than PS and grape verjuice. Within the Sour-Apple-Products the $75^{\circ}$ Brix score significantly the lowest. These results showed that Sour apple concentrate with $65^{\circ}$ Brix with addition of salt or citric acid but not both.
\end{abstract}

Keywords-Apple, Sans Pareille, Apple juice, Sour Apple Concentrate, mouwashah, Citric Acid, Salt, water activity.

\section{INTRODUCTION}

Lebanese "traditional" varieties of apples mainly Red Delicious, Golden Delicious and Sans Pareille (mouwachah) apple, are planted and relatively newer varieties have been introduced such as Gala, Fuji, Scarlett, Super Chief, and Granny Smith. All of these apples had little access to the regional market in last few years due to the regional situation. FAO stats 2013 states that the total Area planted with apples is of 13,604 hectares (ha) producing of 153,151 tons of apples annually constituting $23 \%$ of total Lebanese fruits production [1].

Apple juice has pleasant taste and high concentration of phenolic compounds, vitamins, minerals, dietary fiber and antioxidant capacity [2-4]. Some intrinsic and extrinsic factors affect the properties of Fruit-based products that are assessed by different chemical, physical, and sensory parameters. Intrinsic factors include maturity, cultivar, root-stock and pest resistance. Extrinsic factors include growing region, cultivation practices, climate, water stress, storage conditions and the processing technology, packing and transportation [5]. Industrial products from apples include: apple juice, dried apples, apple vinegar and sweet apple molasses [6].
Sans Pareil is woody perennial and Deciduous Fruit. It is an old apple variety which can be eaten fresh or used for cooking. It blooms in March and is harvested in September. This variety is very sweet and juicy is has a large fruit with orange and yellow skin. It is also one of the highly susceptible varieties to fire-blight. This in addition to the problem of marketing all Lebanese apples made this variety suitable to study its development into a shelf stable product resembling two traditional products in the Lebanese market, mainly grape-verjuice and pomegranate sauce. Noting in fruits the harvest time affected $\mathrm{pH}$, organic acids, sugars, taste, but not aroma [7].

The grape-verjuice is simply the juice of unripe grapes, which is boiled and bottled with a $13^{\circ}$ Brix total soluble solid. The low pH (2.6-2.9) and the optional addition of salt makes this product shelf stable grape-verjuice. As for the pomegranate molasses it is done from pomegranate juice which is thickened by boiling to reach around 65$73^{\circ}$ Brix of total soluble solids and a $\mathrm{pH}$ value ranging from 1.73 to 3 [8]. Unripe apple juice made from apples harvested in July/august was studied and compared to those sauces mentioned above.

Unripe Sour apple concentrate might be a food ingredient that provides acidity and flavor and as an alternative to 
vinegar in salad dressings and other applications where the sensory character of acetic acid is unacceptable [9]. Because it can be produced from unripe apple with fireblight, it might be of great interest to apple growers and to the food industry.

\section{MATERIALS AND METHODS}

\subsection{Sour apple concentrate preparation}

The materials used in this study are unripe Sans Pareille, Malus domestica, (mouwachah) which were collected in end of July, washed and pressed to produce Sour Apple juice of $13^{\circ}$ Brix total soluble solids. This juice was thickened by boiling to have Sour Apple Juice, Sour Apple Concentrate plus salt (1\%), Sour apple concentrate plus citric acid (1\%) and Sour apple concentrate plus both salt and citric acid all with 55, 65 and $75^{\circ}$ Brix total soluble solids (Fig. 1).

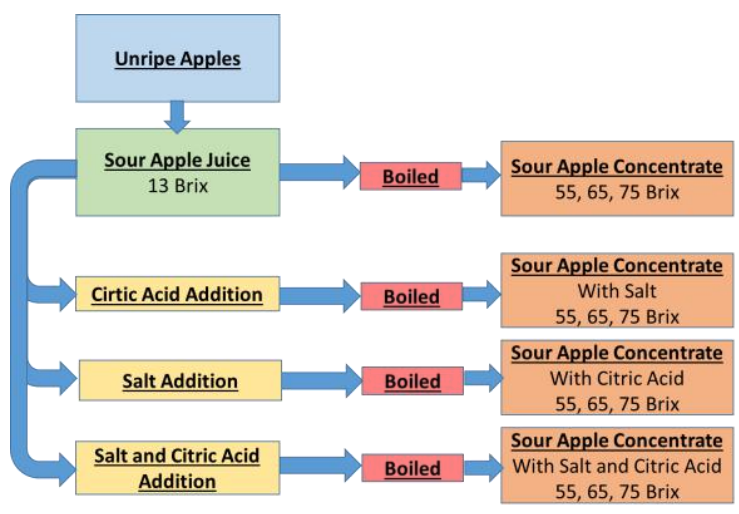

Fig.1: Sour Apple Concentrate production flow

\subsubsection{Sour Apple Juice, Grape-Verjuice and Pomegranate sauce}

Homemade verjuice and pomegranate concentrate were collected and the physico-chemical properties were recorded.

\subsection{Equipment used to measure Physico-chemical properties}

Brix Value: Brix Value was measured using Portable hand held RFM700 refractometer (Bellingham and Stanley LTD. United Kingdom).

Weight determination: Weight was measured using Portable electronic balance Model 727 was used to measure the weight with an accuracy of \pm 1 gr (Jata Hogar).

pH: Microcomputer based pH /conductivity /TDS /salinity and temperature pocket meter Model $\mathrm{pH} / \mathrm{EC} 80$ was used to measure the $\mathrm{pH}$ (Jenco VisionP).

Ash content: Ash was determined using the AOAC 942.05 method.
Volume Determination: 10mL glass graduated cylinder, with sub gradations of $0.1 \mathrm{~mL}$ (Graduated cylinder, tall form, BLAUBRAND®, class A, Boro 3.3, DE-M).

Caloric Value: Bomb calorimeter IKA C200 was used (KA®-Werke GmbH \& Co. KG)

\subsection{Sensory Analysis}

The sensory attributes attained from 35 taste panelists repeated 3 times include: aroma with 1 having no aroma and 9 having best aroma, appearance with 1 having worst appearance and 9 having the best appearance, texture with 1 being the worst and 9 being the best one, sourness with 1 having no sourness and 9 having the highest sourness, sweetness with 1 having no sweetness and 9 having highest sweetness and overall acceptability with 1 having lowest acceptability and 9 having the highest acceptability. In addition to that, the sensory score of each Sour apple concentrate was calculated by taking the mean of the different sensory attributes.

\subsection{Statistical analysis}

All tests and analysis were run in triplicates and averaged. General linear model performed via SPSS (statistical Package for the Social Sciences, version 17.0) was used to study the difference between Sour Apple Juice products in terms of density, caloric content on product basis and on dry matter basis, ash content, $\mathrm{pH}$, titratable acidity (gr/100ml) and total soluble solids per titratable acidity among and within the different Brix.

Furthermore, General linear model performed via SPSS was used to assess the difference between the Sour apple concentrate products, with and without salt, with and without citric acid and with both salt and citric acid taking Brix as a covariate.

To study the effect of Brix on the average score General linear model performed via SPSS was used taking salt and citric acid addition as covariate.

\section{RESULTS}

\subsection{Sour Apple Juice, verjuice, pomegranate}

The Juice extracted from the unripe apples had a brix value of $13^{\circ}$ Brix which comparable to that of verjuice but much lower than that of pomegranate (Table 1). They did differ significantly in terms of $\mathrm{pH}$ where Verjuice showed the lowest and consequently the highest TA and the lowest TSS/TA.

Concerning the juice to concentrate conversion value it was noted that $100 \mathrm{gr}$ of premature apple was needed to produce 61.3gr Apple Juice with $13^{\circ}$ Brix., 14.5gr SAC with $55^{\circ}$ Brix, $12.25 \mathrm{gr} \mathrm{SAC}$ with $65^{\circ} \mathrm{Brix}$ and $10.63 \mathrm{gr} \mathrm{SAC}$ with $75^{\circ}$ Brix. 
Table.1 Sour unripe Apple Juice, Verjuice and pomgranate Physical properties

\begin{tabular}{lccc}
\hline & Apple juice & Verjuice & Pomegranate \\
\cline { 2 - 4 } & Mean \pm SE & Mean \pm SE & Mean \pm SE \\
\hline TSS (Brix) & $13.0 \pm 0.002$ & $13.1 \pm 0.002$ & $65.0 \pm 0.002$ \\
pH & $3.67^{\mathrm{a}} \pm 0.04$ & $2.84^{\mathrm{b}} \pm 0.04$ & $4.04^{\mathrm{c}} \pm 0.04$ \\
$\mathrm{TA}(\mathrm{gr} / 100 \mathrm{ml})$ & $4.53^{\mathrm{a}} \pm 0.96$ & $17.73^{\mathrm{b}} \pm 1.00$ & $10.47^{\mathrm{c}} \pm 0.95$ \\
TSS/TA & $2.87^{\mathrm{a}} \pm 0.031$ & $0.73^{\mathrm{b}} \pm 0.03$ & $6.21^{\mathrm{c}} \pm 0.03$ \\
\hline
\end{tabular}

TSS: Total Soluble Solids; TA: Titratable Acidity;

Among rows means with different letters are significantly different

\subsection{Physicochemical properties}

\subsubsection{Density}

Comparing the density of the different Sour Apple Concentrate (SAC) [10] products within the same brix, showed that the density of the SAC within $55^{\circ}$ Brix was significantly the lowest while there was no difference when comparing densities of SAC with Salt addition (SACSa), SAC with citric acid addition (SACCA), SAC with $\mathrm{Sa}$ and $\mathrm{CA}$ addition (SACSaCA). This difference, however, difference disappeared within 65 and $75^{\circ}$ Brixes (Table 2).

Table.2: Density of different sour apple concentrate products

\begin{tabular}{|c|c|c|c|}
\hline \multirow[t]{2}{*}{ Brix } & 55 & 65 & 75 \\
\hline & Mean $\pm \mathrm{SE}$ & Mean \pm SE & Mean $\pm \mathrm{SE}$ \\
\hline SAC & $1.257^{\mathrm{a} 1} \pm 0.002$ & $1.320^{\mathrm{b} 1} \pm 0.002$ & $1.362^{\mathrm{c} 1} \pm 0.002$ \\
\hline SACSa & $1.264^{\mathrm{a} 2} \pm 0.002$ & $1.319^{\mathrm{b} 1} \pm 0.002$ & $1.359^{c 1} \pm 0.002$ \\
\hline SACCA & $1.264^{\mathrm{a} 2} \pm 0.002$ & $1.310^{\mathrm{b} 2} \pm 0.002$ & $1.361^{\mathrm{c} 1} \pm 0.002$ \\
\hline SACSaCA & $1.270^{\mathrm{a} 2} \pm 0.002$ & $1.323^{\mathrm{b} 1} \pm 0.002$ & $1.363^{\mathrm{c} 1} \pm 0.002$ \\
\hline
\end{tabular}

Within the same product the density of SAC, SACSa and SACA as expected was significantly higher the higher the brix value. The density of SACSaCA was significantly the highest at $75^{\circ}$ Brix, this significance did not show between the 55 and $65^{\circ}$ Brix (Table 2).

3.2.2 Caloric content product basis and dry matter basis The total caloric content within the product type is as expected where the higher the brix value the significantly higher the caloric content. (Table 3). Furthermore, within the same Brix, 55, 65 and 75, there was no significant difference in the caloric value (Calorie/100gr Product) between SAC, SACSa, SACCA and SACSaCA
Table.3:Caloric content of different sour apple concentrate products per 100 gr product

\begin{tabular}{llll}
\hline Brix & \multicolumn{1}{c}{55} & 65 & 75 \\
\cline { 2 - 4 } & Mean \pm SE & Mean \pm SE & Mean \pm SE \\
\hline SAC & $172.13^{\mathrm{a}}{ }^{1} \pm 2.75$ & $207.84^{\mathrm{b} 1} \pm 2.75$ & $233.72^{\mathrm{c} 1} \pm 2.75$ \\
SACSa & $177.06^{\mathrm{a}}{ }^{1} \pm 2.75$ & $206.04^{\mathrm{b} 1} \pm 2.75$ & $237.27^{\mathrm{c}}{ }^{1} \pm 2.75$ \\
SACCA & $174.36^{\mathrm{a}}{ }^{1} \pm 2.75$ & $206.37^{\mathrm{b}} \pm 2.75$ & $233.40^{1}{ }_{\mathrm{c} 1} \pm 2.75$ \\
SACSaCA & $176.75^{\mathrm{a}}{ }^{1} \pm 2.75$ & $207.10^{\mathrm{b} 1} \pm 2.75$ & $234.77^{\mathrm{c}}{ }^{1} \pm 2.75$ \\
\hline SAC: Sour Apple Concentrate, Sa: Salt, CA: Citric Acid; \\
Among rows: means with different letters are significantly different; \\
Among Columns: means with different numbers are significantly different
\end{tabular}

The caloric content per dry matter within SAC, SACSa, SACCA and SACSaCA among the different brixes did not differ significantly. The same is true concerning the caloric content of the different SAC products, with and without salt and citric acid, where it did not differ significantly (Table 4).

Table.4 Caloric content of different sour apple concentrate products per 1 gr Dry Matter

\begin{tabular}{llll}
\hline Brix & \multicolumn{1}{c}{55} & \multicolumn{1}{c}{75} \\
\cline { 2 - 4 } & Mean \pm SE & Mean \pm SE & Mean \pm SE \\
\hline SAC & $3.107^{\mathrm{a}}{ }^{1} \pm 0.044$ & $3.163^{\mathrm{a} 1} \pm 0.041$ & $3.127^{\mathrm{a}}{ }^{1} \pm 0.04$ \\
SACSa & $3.144^{\mathrm{a}}{ }^{1} \pm 0.044$ & $3.136^{\mathrm{a} 1} \pm 0.041$ & $3.176^{\mathrm{a}}{ }^{\mathrm{1}} \pm 0.04$ \\
SACCA & $3.092^{\mathrm{a}}{ }^{1} \pm 0.045$ & $3.185^{\mathrm{a}}{ }^{1} \pm 0,041$ & $3.120^{\mathrm{a} 1} \pm 0.04$ \\
SACSaCA & $3.134^{\mathrm{a}}{ }^{1} \pm 0.046$ & $3.134^{\mathrm{a}}{ }^{1} \pm 0.058$ & $3.140^{\mathrm{a}}{ }^{\mathrm{1}} \pm 0.04$ \\
\hline SAC: Sour Apple Concentrate, Sa: Salt, CA: Citric Acid; \\
Among rows: means with different letters are significantly different; \\
Among Columns: means with different numbers are significantly different
\end{tabular}

\subsubsection{Water Activity}

As expected the higher the brix value the significantly lower the water activity within the different SAC products (Table 5).

Table. 5 Water activity of the different SAC products

\begin{tabular}{lccl}
\hline Brix & 55 & 65 & 75 \\
\cline { 2 - 4 } & Mean \pm SE & Mean \pm SE & Mean \pm SE \\
\hline SAC & $0.976^{\mathrm{a}}{ }^{\mathrm{a}} \pm 0.116$ & $0.84^{\mathrm{b}}{ }^{\mathrm{b}} \pm 0.046$ & $0.715^{\mathrm{c}} \pm 0.047$ \\
SACSa & $0.97^{\mathrm{a}}{ }^{1} \pm 0.112$ & $0.809^{\mathrm{b}} \pm 0.046$ & $0.701^{\mathrm{c}}{ }^{1} \pm 0.044$ \\
SACCA & $0.971^{\mathrm{a}}{ }^{\mathrm{a}} \pm 0.133$ & $0.868^{\mathrm{b}}{ }^{3} \pm 0.046$ & $0.714^{\mathrm{c}}{ }^{1} \pm 0.045$ \\
SACSaCA & $0.97^{\mathrm{a}}{ }^{1} \pm 0.135$ & $0.795^{\mathrm{b}}{ }^{2} \pm 0.044$ & $0.671^{\mathrm{c}}{ }^{2} \pm 0.044$ \\
\hline SAC: Sour Apple Concentrate, Sa: Salt, CA: Citric Acid; \\
Among rows: means with different letters are significantly different; \\
Among Columns: means with different numbers are significantly different
\end{tabular}

Within the $55^{\circ}$ Brix the water activity did not differ significantly between the water activity values of SAC, SACSa, SACCA and SACSaCA. Within $75^{\circ}$ Brix the water activity value of SACSaCA was significantly the lowest with the difference in water activity values of SAC, SACSa and SACCA was not significant (Table 5). 


\subsubsection{Ash content}

As for the Ash-content within SAC showed no significant difference among the different Brixes. Within SACSa and SACCA the ash content at 55 and $65^{\circ}$ Brix did not show any significant difference both being significantly lower than the ash content at $75^{\circ}$ Brix. Within SACSaCA the ash content at $55^{\circ}$ Brix was significantly lower from those 65 and $75^{\circ}$ Brix whose ash content did not differ significantly from each other (Table 6).

Table.6 Ash content per product ( $g r / g r)$

\begin{tabular}{lccc}
\hline Brix & \multicolumn{2}{c}{55} & \multicolumn{1}{c}{75} \\
\cline { 2 - 4 } & Mean \pm SE & Mean \pm SE & Mean \pm SE \\
\hline SAC & $0.004^{\mathrm{a} 1} \pm 0.002$ & $0.005^{\mathrm{a} 1} \pm 0.001$ & $0.006^{\mathrm{a} 1} \pm 0.04$ \\
SACSa & $0.011^{\mathrm{a}}{ }^{1} \pm 0.002$ & $0.014^{\mathrm{a}}{ }^{2} \pm 0.001$ & $0.016^{\mathrm{b} 2} \pm 0.04$ \\
SACCA & $0.011^{\mathrm{a} 2} \pm 0.002$ & $0.014^{\mathrm{a} 2} \pm 0.001$ & $0.016^{\mathrm{b} 2} \pm 0.04$ \\
SACSaCA & $0.020^{\mathrm{a}}{ }^{3} \pm 0.002$ & $0.025^{\mathrm{b} 3} \pm 0.002$ & $0.028^{\mathrm{b} 3} \pm 0.04$ \\
\hline SAC: Sour Apple Concentrate, Sa: Salt, CA: Citric Acid; \\
Among rows: means with different letters are significantly different; \\
Among Columns: means with different numbers are significantly different
\end{tabular}

\subsection{5 $\mathrm{pH}$}

The $\mathrm{pH}$ within the SAC and SACSa showed no significant difference between 55 and $65^{\circ}$ Brix with $\mathrm{pH}$ at $75^{\circ} \mathrm{Brix}$ being significantly the lowest (Table 7).

Within $55^{\circ}$ Brix, the $\mathrm{pH}$ of $\mathrm{SAC}$ was significantly the highest compared to $\mathrm{pH}$ of SACSa and SACCA, which did not differ significantly from each other. The $\mathrm{pH}$ of SACSaCA was significantly the lowest (Table 7).

Table. 7 pH of the different Sour apple concentrate

\begin{tabular}{lccl}
\hline Brix & 55 & 65 & 75 \\
\cline { 2 - 4 } & Mean \pm SE & Mean \pm SE & Mean \pm SE \\
\hline SAC & $3.069^{\mathrm{a}}{ }^{1} \pm 0.04$ & $2.983^{\mathrm{a}}{ }^{\mathrm{1}} \pm 0.038$ & $1.877^{\mathrm{b}}{ }^{1} \pm 0.037$ \\
SACSa & $2.942^{\mathrm{a}}{ }^{2} \pm 0.04$ & $2.840^{\mathrm{a}}{ }^{2} \pm 0.037$ & $1.923^{\mathrm{b}}{ }^{1} \pm 0.037$ \\
SACCA & $2.870^{\mathrm{a}}{ }^{2} \pm 0.041$ & $2.727^{\mathrm{b}}{ }^{3} \pm 0.037$ & $1.780^{\mathrm{c}}{ }^{1} \pm 0.037$ \\
SACSaCA & $2.760^{\mathrm{a}}{ }^{3} \pm 0.042$ & $2.592^{\mathrm{b}}{ }^{4} \pm 0.053$ & $1.930^{\mathrm{c}}{ }^{1} \pm 0.037$ \\
\hline SAC: Sour Apple Concentrate, Sa: Salt, CA: Citric Acid; \\
Among rows: means with different letters are significantly different; \\
Among Columns: means with different numbers are significantly different
\end{tabular}

Within $65^{\circ}$ Brix the $\mathrm{pH}$ of all SAC products differ significantly from each other with SAC being significantly the highest, followed by the $\mathrm{pH}$ of SACSa and by the $\mathrm{pH}$ of SACCA and SACSaCA being significantly the lowest (Table 7).

Within the $75^{\circ}$ Brix the $\mathrm{pH}$ of SAC, SACSa, SACCA and SACSaCA did not differ significantly from each other (Table 7).

3.2.6 Titratable Acidity and Total Soluble Solids per Titratable acidity
Titratable Acidity within the SAC products showed that the higher the Brix the significantly higher the Titratable Acidity (Table 8).

Within the same Brix the SACCA had the significantly highest Titratable Acidity, followed by the Titratable Acidity of the SACSaCA which is significantly higher than the SACSa and SAC which were significantly the lowest (Table 8).

Table. 8 Titratable Acidity ( $\mathrm{gr} / 100 \mathrm{ml})$ of the different Sour Apple products

\begin{tabular}{lccc}
\hline Brix & 55 & 65 & 75 \\
\cline { 2 - 4 } & Mean \pm SE & Mean \pm SE & Mean \pm SE \\
\hline SAC & $37.18^{\mathrm{a} 1} \pm 1.06$ & $40.69^{\mathrm{b} 1} \pm 0.97$ & $49.43^{\mathrm{c} 1} \pm 0.96$ \\
SACSa & $35.77^{\mathrm{a}}{ }^{1} \pm 1.05$ & $43.35^{\mathrm{b} 1} \pm 0.98$ & $49.40^{\mathrm{c} 1} \pm 0.96$ \\
SACCA & $50.49^{\mathrm{a} 2} \pm 1.08$ & $62.75^{\mathrm{b} 2} \pm 0.98$ & $95.19^{\mathrm{c} 2} \pm 0.96$ \\
SACSaCA & $46.47^{\mathrm{a}}{ }^{3} \pm 1.09$ & $47.57^{\mathrm{a} 3} \pm 1.39$ & $53.65^{\mathrm{b} 3} \pm 0.96$ \\
\hline SAC: Sour Apple Concentrate, Sa: Salt, CA: Citric Acid; \\
Among rows: means with different letters are significantly different; \\
\multicolumn{4}{l}{ Among Columns: means with different numbers are significantly different }
\end{tabular}

Within SAC and SACSa the brix had no clear significant effect on the Total Soluble Solids per Titratable Acidity (TSS/TA). Within SACCA where the TSS/TA at 55 and $65^{\circ}$ Brix were significantly higher than TSS/TA at $75^{\circ}$ Brix. Within SACSaCA the TSS/TA at $55^{\circ}$ Brix was significantly the lowest where the TSS/TA at 65 and $75^{\circ}$ Brix did not differ significantly (Table 9 ).

Table.9 Total Soluble Solids (Brix) per Titratable Acidity ( $\mathrm{gr} / 100 \mathrm{ml})$ of the different Sour Apple products

\begin{tabular}{llll}
\hline Brix & \multicolumn{1}{c}{55} & \multicolumn{1}{c}{65} \\
\cline { 2 - 4 } & Mean \pm SE & Mean \pm SE & Mean \pm SE \\
\hline SAC & $1.495^{\mathrm{a} 1} \pm 0.031$ & $1.613^{\mathrm{b} 1} \pm 0.031$ & $1.512^{\mathrm{a} 1} \pm 0.031$ \\
SACSa & $1.583^{\mathrm{a}}{ }^{\mathrm{a}} \pm 0.031$ & $1.515^{\mathrm{a} 2} \pm 0.031$ & $1.513^{\mathrm{a}}{ }^{1} \pm 0.031$ \\
SACCA & $1.119^{\mathrm{a} 2} \pm 0.031$ & $1.032^{\mathrm{a}}{ }^{3} \pm 0.031$ & $0.787^{\mathrm{b}}{ }^{2} \pm 0.031$ \\
SACSaCA & $1.217^{\mathrm{a}} \pm 0.031$ & $1.391^{\mathrm{b} 4} \pm 0.031$ & $1.394^{\mathrm{b}} \pm 0.031$ \\
\hline SAC: Sour Apple Concentrate, Sa: Salt, CA: Citric Acid; & \\
Among rows: means with different letters are significantly different; \\
Among Columns: means with different numbers are significantly different
\end{tabular}

Within the same Brix the SACCA had the significantly lowest TSS/TA, followed by the Titratable Acidity of the SACSaCA which is significantly lower than the SACSa and SAC which were significantly the highest (Table 9).

\subsection{Sensory Attributes}

\subsubsection{Aroma}

The aroma score of pomegranate concentrate was significantly the lowest followed by verjuice and SACSaCA which did not differ significantly. Furthermore, verjuice did not differ significantly from SACSa, SAC and SACSa possessed the highest aroma scores (Fig.2). 


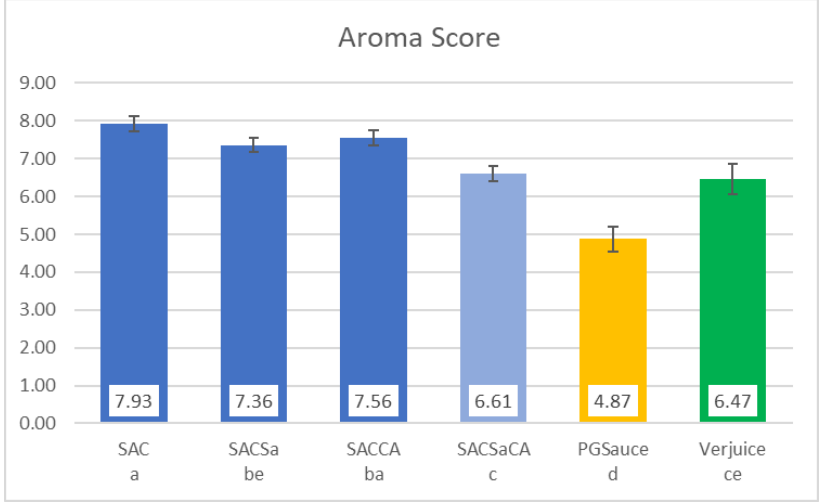

Fig.2 Aroma Score of different Sour Apple concentrate products, pomegranate sauce and verjuice

SAC: Sour Apple Concentrate, Sa: Salt, CA: Citric Acid; PG: Pomegranate; Product means with different letters are significantly different

\subsubsection{Appearance}

The pomegranate concentrate score significantly the lowest score in terms of appearance followed by SACSaCA and Verjuice with SAC, SACCA and SACSa being the highest (Fig. 3).

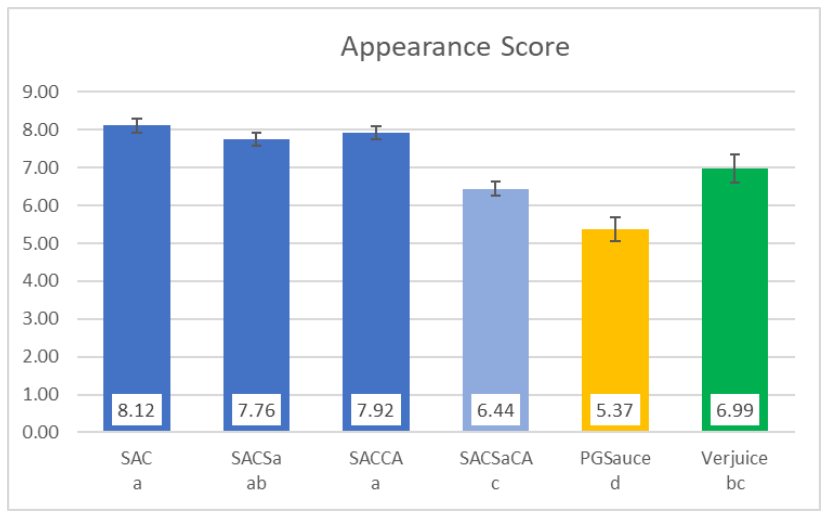

Fig.3 Appearance Score of different Sour Apple concentrate products, pomegranate sauce and verjuice SAC: Sour Apple Concentrate, Sa: Salt, CA: Citric Acid; PG: Pomegranate; Product means with different letters are significantly different

\subsubsection{Texture}

The Texture score of pomegranate is significantly the lowest followed by SACSaCA and Verjuice with SAC, SACCA and SACSa being the highest (Fig. 4).

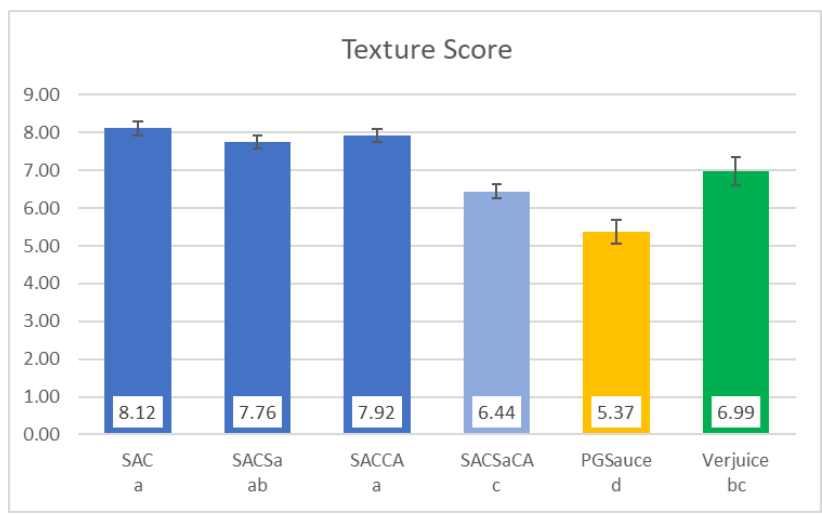

Fig.4 Texture Score of different Sour Apple concentrate products, pomegranate sauce and verjuice

SAC: Sour Apple Concentrate, Sa: Salt, CA: Citric Acid; PG: Pomegranate; Product means with different letters are significantly different

\subsubsection{Sourness}

The score of sourness was significantly the lowest for pomegranate sauce and SACSaCA followed by the verjuice which did not differ significantly from SAC, SACSa and SACCA which tended to have the highest score (Fig. 5).

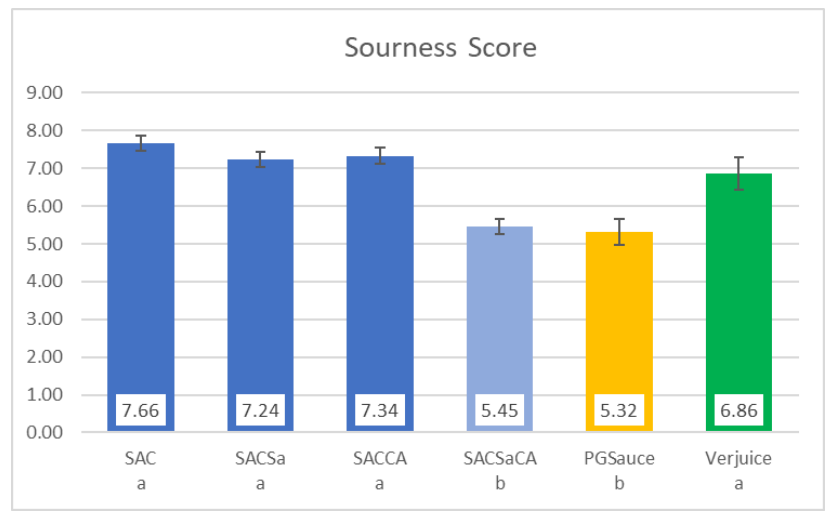

Fig.5 Sourness Score of different Sour Apple concentrate products, pomegranate sauce and verjuice

SAC: Sour Apple Concentrate, Sa: Salt, CA: Citric Acid; PG: Pomegranate; Product means with different letters are significantly different

\subsubsection{Sweetness}

The pomegranate have the significantly lowest score although it did not differ significantly from the verjuice. The SACSa sweetness score had the significantly highest score. The SACSaCA, SAC and SACA score were in between and in descending order (Fig. 6). 


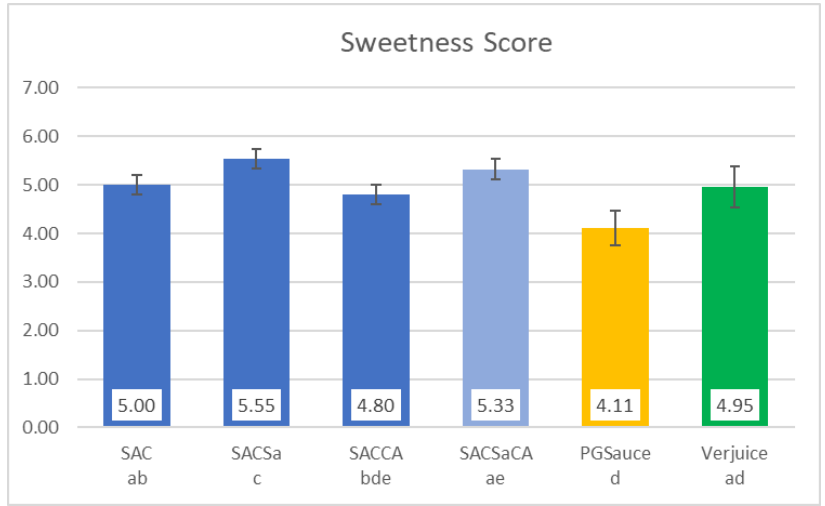

Fig.6 Sweetness Score of different Sour Apple concentrate products, pomegranate sauce and verjuice

SAC: Sour Apple Concentrate, Sa: Salt, CA: Citric Acid; PG: Pomegranate; Product means with different letters are significantly different

\subsubsection{Taste}

The taste scores of the pomegranate followed by SACSaCA are significantly lower than SACSa, SACCA and SAC possessing the highest score. Concerning grape verjuice is not significantly different from pomegranate, SACSaCA and SACSa (Fig. 7).

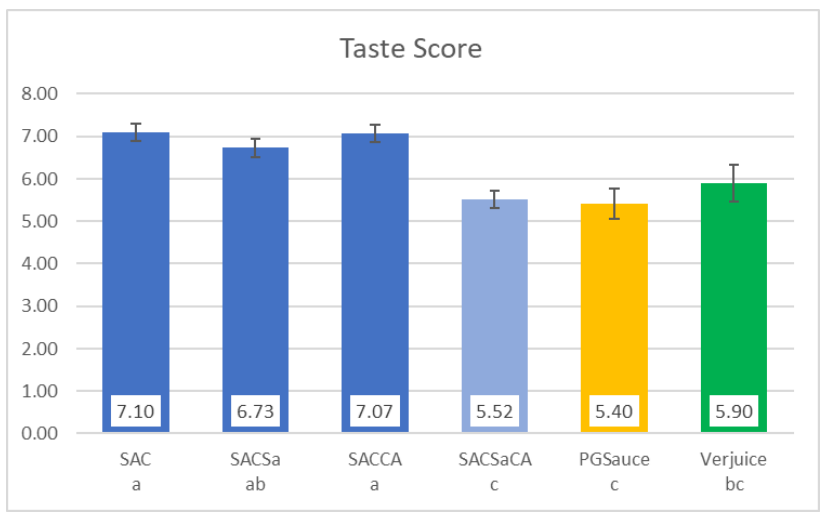

Fig.7 Taste Score of different Sour Apple concentrate products, pomegranate sauce and verjuice

SAC: Sour Apple Concentrate, Sa: Salt, CA: Citric Acid; PG: Pomegranate; Product means with different letters are significantly different

\subsubsection{Average Score}

The average scores of the pomegranate is significantly lower than all SAC products and verjuice and not from SACSaCA. There is no significant difference between the average scores of SAC, SACSa and SACCA and all are significantly than the SACSaCA, pomegranate and grape verjuice (Fig. 8).

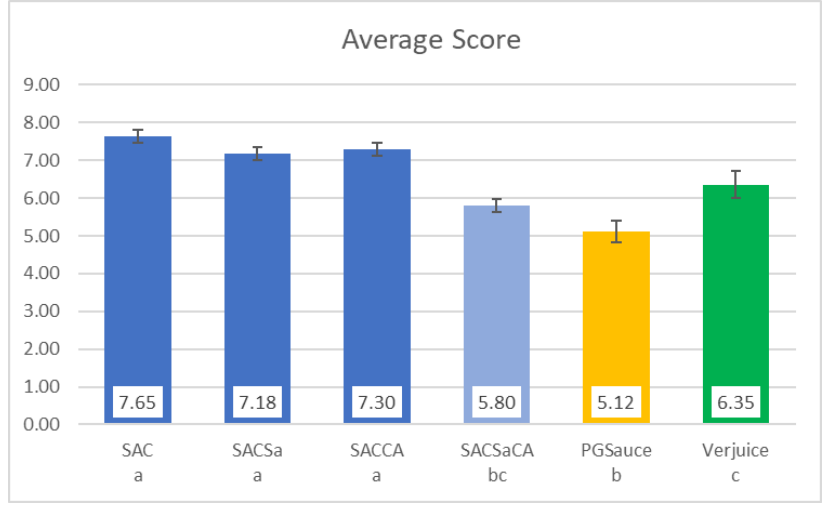

Fig.8 Average Score of different Sour Apple concentrate products, pomegranate sauce and verjuice

SAC: Sour Apple Concentrate, Sa: Salt, CA: Citric Acid; PG: Pomegranate; Product means with different letters are significantly different

There was no significant difference of the sour apple concentrate of 55 and $65^{\circ}$ Brix. The average score of the sour apple concentrate of $75^{\circ}$ Brix scored significantly the lowest (Fig. 9).

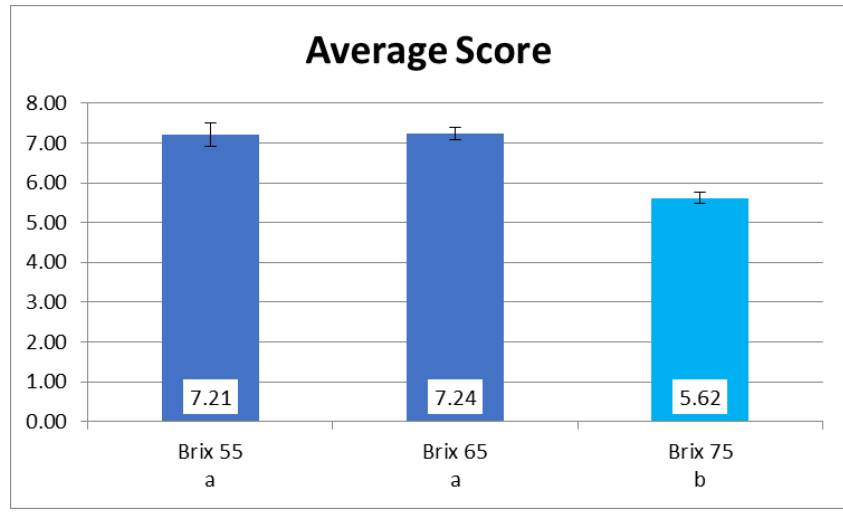

Fig.9 Average Score of different Sour Apple concentrate Brix

SAC: Sour Apple Concentrate, Sa: Salt, CA: Citric Acid; PG: Pomegranate; Product means with different letters are significantly different

\section{DISCUSSION}

The level of efficiency is calculated by the gr of juice per $100 \mathrm{gr}$ of apples. As for the character of the sour apple juice in terms of $\mathrm{pH}$ which is lower than 4.2 thus starting as a high acid food and the higher the brix the lower the $\mathrm{pH}$. This was reflected in titratable acidity which is higher the higher the Brix and with citric acid addition the much higher the titratable acidity. Furthermore, the ripening index [11] of apples, total soluble solids (Brix) per titratable acidity $(\mathrm{gr} / 100 \mathrm{ml})$ for this study was recorded and sets a benchmark for future studies.

As for the density of sour apple concentrate, it is an important factor to calculate the weight and size of bottle in terms one portion. In addition to that based on this one can study the efficiency of transportation. Taking into 
consideration the higher the Brix, the higher the density. The caloric content as expected was higher with increasing brix. This is an important information since the new trend in the $21^{\text {st }}$ century is wellness.

Concerning the water activity it is a tool to know the type of the product and to be the basis for future shelf life studies in combination with the $\mathrm{pH}$, titratable acidity and Total Soluble Solids per Titratable Acidity.

After setting the physicochemical properties, the sensory analysis study the perception of people for the apple based new product namely the Sour Apple concentrate in comparison with two traditional products: pomegranate and grape verjuice.

The aroma of the verjuice is scored higher than that of pomegranate which might be due to processing method. The verjuice might be boiled but that of pomegranate it is not only boiled but condensed through evaporation [12]. The aroma of the condensed sour apple concentrate scored higher than pomegranate sauce although it possessed similar production method [13]. This is true in all the other sensory attributes except for the sweetness where those having salt addition, including verjuice [14], had higher scores than those without. This might be because a pinch of salt would increase the sweetness perception. The average score showed that the sour apple concentrate products except the one with both citric acid and salt was significantly higher than the pomegranate sauce and verjuice. In addition to that, the average score of $75^{\circ}$ Brix was lowest thus $65^{\circ}$ Brix should be considered as the highest concentration.

\section{CONCLUSION}

The sour apple concentrate $75^{\circ}$ Brix showed lower $\mathrm{pH}$ and water activity, but in terms of sensory score, the 55 and $65^{\circ}$ Brix scored higher thus should be considered. Unripe apple juice made from apples harvested in July/august can be used to produce Sour apple concentrate a food ingredient that provides acidity and flavor and as an alternative to verjuice and pomegranate sauce in salad dressings and other applications where it scored higher than both [15]. Citric acid addition or salt addition can be used to add some protection to the product. But it is not advised to use both salt and citric acid together. This is a product of interest to apple growers and to the food industry since it increase the potential of having a product with relatively long shelf.

\section{ACKNOWLEDGEMENTS}

Thanks for the Lebanese association of food scientists and technologists for connecting us with Sans Pareil growers.

\section{REFERENCES}

[1] FAO, FAOSTAT. Food and Agriculture Organization of the United Nations. 2013.

[2] Feliciano, R.P., et al., Characterization of traditional and exotic apple varieties from Portugal. Part 1 - Nutritional, phytochemical and sensory evaluation. Journal of Functional Foods, 2010. 2(1): p. 35-45.

[3] Kalinowska, M., et al., Apples: content of phenolic compounds vs. variety, part of apple and cultivation model, extraction of phenolic compounds, biological properties. Plant Physiol Biochem, 2014. 84: p. 169-188.

[4] Liaudanskas, M., et al., A Comparative Study of Phenolic Content in Apple Fruits. International Journal of Food Properties, 2015. 18(5): p. 945-953.

[5] Magerramov, M., Density of the concentrates of peach and pome granate juices at elevated state parameters. Journal of Engineering Physics, 2006. 79: p. 811-816.

[6] Dupas de Matos, A., et al., Use of verjuice as an acidic salad seasoning ingredient: evaluation by consumers' liking and Check-All-That-Apply. European Food Research and Technology, 2018.

[7] Dupas de Matos, A., et al., Chemical and sensory analysis of verjuice: An acidic food ingredient obtained from unripe grape berries. Innovative Food Science \& Emerging Technologies, 2017. 44: p. 9-14.

[8] Yilmaz, Y., I. Celik, and F. Isik, Mineral composition and total phenolic content of pomegranate molasses. Journal of Food, Agriculture and Environment, 2007. 5.

[9] Hakim, B.N., et al., Influence of Fruit and Vegetable Intake on Satiety and Energy Intake: A Review. Sains Malaysiana, 2018. 47: p. 2381-2390.

[10] Paduano, A., et al., Microwave and ultrasound-assisted extraction of capsaicinoids from chili peppers (Capsicum annuum L.) in flavored olive oil. Journal of Food Research, 2014. 3(4): p. 51.

[11] Włodarska, K., et al., Classification of commercial apple juices based on multivariate analysis of their chemical profiles. International Journal of Food Properties, 2017. 20(8): p. 1773-1785.

[12] Incedayi, B., C. Tamer, and O.U. Copur, Aresearch on the composition of Pomegranate molasses. Journal of Agri. Fac., 2010. 24: p. 37-47.

[13] Naveena, B., et al., Antioxidant activity of pomegranate rind powder extract in cooked chicken patties. International Journal of Food Science \& Technology, 2008. 43: p. 18071812 .

[14] Martí, N., A. Pérez-Vicente, and C. García-Viguera, Influence of storage temperature and ascorbic acid addition on pomegranate juice. Journal of the Science of Food and Agriculture, 2002. 82(2): p. 217-221.

[15] Labbé, M., et al., Characterization of chemical compositions and bioactive compounds in juices from pomegranates (Wonderful, Chaca and Codpa) at different maturity stages. Chilean journal of agricultural research, 2016. 76: p. 479-486. 